\title{
LGMD2I in a North American population
}

\author{
Peter B Kang ${ }^{\dagger 1,2}$, Chris A Feener ${ }^{\dagger 1}$, Elicia Estrella ${ }^{1}$, Marielle Thorne ${ }^{1}$, \\ Alexander J White ${ }^{1}$, Basil T Darras ${ }^{2}$, Anthony A Amato ${ }^{4}$ and \\ Louis M Kunkel*1,3
}

\begin{abstract}
Address: ${ }^{1}$ Program in Genomics, Children's Hospital Boston and Harvard Medical School, Boston, USA, ${ }^{2}$ Department of Neurology, Children's Hospital Boston and Harvard Medical School, Boston, USA, ${ }^{3}$ Howard Hughes Medical Institute, Children's Hospital Boston, Boston, USA and ${ }^{4}$ Department of Neurology, Brigham and Women's Hospital and Harvard Medical School, Boston, USA

Email: Peter B Kang - peter.kang@childrens.harvard.edu; Chris A Feener - feener@enders.tch.harvard.edu; Elicia Estrella - elicia.estrella@childrens.harvard.edu; Marielle Thorne - thorne@enders.tch.harvard.edu; Alexander J White - alexander.white@childrens.harvard.edu; Basil T Darras - basil.darras@childrens.harvard.edu; Anthony A Amato - aamato@partners.org; Louis M Kunkel* - kunkel@enders.tch.harvard.edu

* Corresponding author †Equal contributors
\end{abstract}

Published: 24 November 2007

BMC Musculoskeletal Disorders 2007, 8:115 doi:10.1 I86/147I-2474-8-II5

This article is available from: http://www.biomedcentral.com/I47I-2474/8/I I5

(C) 2007 Kang et al; licensee BioMed Central Ltd.

This is an Open Access article distributed under the terms of the Creative Commons Attribution License (http://creativecommons.org/licenses/by/2.0), which permits unrestricted use, distribution, and reproduction in any medium, provided the original work is properly cited.

\begin{abstract}
Background: There is a marked variation in clinical phenotypes that have been associated with mutations in FKRP, ranging from severe congenital muscular dystrophies to limb-girdle muscular dystrophy type 2l (LGMD2l).

Methods: We screened the FKRP gene in two cohorts totaling 87 patients with the LGMD phenotype.

Results: The c.826C>A, p.L276I mutation was present in six patients and a compound heterozygote mutation in a seventh patient. Six patients had a mild LGMD2I phenotype, which resembles that of Becker muscular dystrophy. The other patient had onset before the age of 3 years, and thus may follow a more severe course.
\end{abstract}

Conclusion: These findings suggest that LGMD2I may be common in certain North American populations. This diagnosis should be considered early in the evaluation of LGMD.

\section{Background}

Fukutin-related protein (FKRP) is encoded by the gene FKRP and participates in the glycosylation of $\alpha$-dystroglycan in the muscle fiber[1]. There is evidence to suggest that the protein localizes to both the Golgi apparatus[1] and the endoplasmic reticulum[2], with some debate over the possibility that mislocalization of FKRP plays a role in the pathogenesis of disease [3-5]. Mutations in FKRP can cause a range of phenotypes, including MDC1C (a severe congenital muscular dystrophy) [6], Walker-Warburg syndrome[7], muscle-eye-brain disease[7], a severe form of limb-girdle muscular dystrophy type 2I (LGMD2I), and a 
mild form of LMGD2I[8]. One particular mutation, c.826C>A, p.L276I, is by far the most common mutation causing LGMD2I, present either in homozygote form or as part of a compound heterozygote genotype [8-12]. Since the original descriptions of these associations, it has become evident that LGMD2I is one of the more common LGMDs in the United Kingdom [13], Denmark[10], and Brazil[12]. A recent series also suggests the same for the United States[14]. We have similarly found that LGMD2I may be one of the more common LGMDs in two North American cohorts.

\section{Methods}

In the first cohort, 63 patients were ascertained either prospectively at the Children's Hospital Boston Neuromuscular Program or by referral from other neurologists in North America for the possible diagnosis of LGMD. Clinical data collected included age of onset, pattern of muscle involvement, family history, creatine kinase (CK) level in serum, and cardiac involvement. All subjects had progressive muscle weakness and myopathic findings on muscle biopsy. We enrolled patients without a known molecular etiology into the first cohort under an institutionally approved protocol. Informed consent was obtained from all patients in this cohort. In the second cohort, one of the authors (AAA) screened 24 patients from his clinic with the clinical diagnosis of LGMD for mutations in FKRP and other genes known to cause LGMD, using clinically available genetic testing for mutations in CAPN3, DYSF, and CAV3. Facioscapulohumeral muscular dystrophy and Duchenne/Becker muscular dystrophies were excluded by genetic testing. Dysferlinopathies were also excluded in the second cohort by Western blot. In both cohorts, patients thought to have Duchenne or Becker muscular dystrophy without known mutations were included. Many of the enrolled patients had muscle biopsies performed at other centers, and thus the immunohistochemistry stains obtained vary from patient to patient. The methods described below apply to the first cohort.

For exon 4 amplification, the primers used were agctgctggacttgaccttc (forward) and tccaagtagatgccaggtc (reverse). The Fast Start Taq DNA Polymerase Kit (Roche Diagnostics, Pleasanton, CA) was used to set up the PCR reactions, which were run at $95^{\circ} \mathrm{C}$ for 4 minutes, followed by 35 cycles of $95^{\circ} \mathrm{C}$ for 30 seconds, $60^{\circ} \mathrm{C}$ for 30 seconds, and $72^{\circ} \mathrm{C}$ for 2 minutes, followed by $72^{\circ} \mathrm{C}$ for 7 minutes.

For the exon 4 sequencing reaction, the primers used were ccgagtttgtggccctagta (forward) and ccagcttctctcatgctct (reverse). The sequences were visualized on the 3730 DNA Analyzer (Applied Biosystems, Foster City, CA) and interpreted using the Sequencher 4.6 software program (Gene Codes Corporation, Ann Arbor, MI). Positive results were confirmed on separate aliquots of DNA that were processed and analyzed in a CLIA-approved DNA diagnostic facility.

Fifty-six of the patients in cohort 1 were also screened for mutations in CAV3 using direct sequencing methods (primers kindly contributed by RR Bennett).

\section{Results}

Among the 63 LGMD patients in the first cohort, 40 were male and 23 female. The age of onset ranged widely from birth to 70 years. The ethnic backgrounds included 38 Caucasians, 7 Hispanic-Americans, 5 African-Americans, 4 Asian-Americans, and 9 unknown. Four patients in the first cohort, all from the United States, were diagnosed with LGMD2I based on mutations in FKRP. Among the 24 LGMD patients in the second cohort, 3 were diagnosed with LGMD2I, 8 with Becker muscular dystrophy, 2 with LGMD2A, 5 with dysferlinopathy (3 with LGMD2B, 2 with Miyoshi myopathy), 1 with FSHD (facial sparing), and 5 are undiagnosed to date.

Demographic and clinical information on the seven patients diagnosed with LGMD2I are listed in Table 1. Patient 1 had onset of symptoms as a toddler, while the others developed symptoms later in childhood or in early adulthood. Age of onset was defined as the age when patients recalled first having motor difficulties, not the age of presentation. None had significant motor delays. Each patient was sporadic, consistent with a recessive pattern of inheritance. The pattern of weakness was predominantly proximal, with the lower extremities more severely affected than the upper extremities. Facial strength was generally preserved, while mild scapular winging was present in some patients. Evidence of mild cardiac or respiratory dysfunction was present in some patients. All of the patients were ambulatory at the last known follow-up. Muscle biopsy was performed in patients 1 through 6 . Histochemical stains demonstrated variation in fiber size, degenerating and regenerating fibers, increased endomysial or perimysial connective tissue, and fiber splitting. Immunohistochemical findings are listed in Table 1.

The first six patients described in Table 1 have homozygous c.826C>A, p.L276I mutations in FKRP. The seventh patient is a compound heterozygote, with a 169 base pair deletion in one allele and a c.328C>T, p.R110W mutation in the other allele. The entire coding region of FKRP was screened in the remaining 59 patients from the first cohort who did not have the common mutation. No other mutations were identified. No mutations in CAV3 were identified in either cohort.

\section{Discussion}

It is becoming increasingly clear that LGMD2I, caused by mutations in FKRP, is one of the more common LGMDs, 


\begin{tabular}{|c|c|c|c|c|c|c|c|}
\hline & Patient I & Patient 2 & Patient 3 & Patient 4 & Patient 5 & Patient 6 & Patient 7 \\
\hline Gender & Male & Male & Female & Male & Female & Female & Male \\
\hline Ethnicity & - & Causasian & Caucasian & Caucasian & Caucasian & Caucasian & Asian \\
\hline Onset & 34 months & Ist grade & $18-19$ years & Childhood & 23 years & Childhood & 25 years \\
\hline Chief complaint & Difficulty rising & Difficulty running & Exertional myalgias & Difficulty running & Difficulty with stairs & Difficulty running & Difficulty with stairs \\
\hline Calf pseudohypertrophy & Present & - & None & Present & None & Present & Medial calf atrophy \\
\hline Heel cords & Contracted & - & Normal & Unknown & Contracted & Normal & - \\
\hline Facial strength & Normal & Mild weakness & Normal & Normal & Normal & Normal & Normal \\
\hline Scapular winging & - & - & - & - & Subtle & Subtle & Subtle \\
\hline Proximal upper extremity strength & - & $4+$ & $4-$ & 5 & $4-$ & 4 & $4+$ \\
\hline Distal upper extremity strength & - & 5 & 5 & 5 & $4+$ to 5 & $4+$ & 5 \\
\hline Proximal lower extremity strength & Weak & $2+$ to $3+$ & 3- to $4-$ & 2 to 3 & 2 & 3 - to 3 & 3- to $4-$ \\
\hline Distal lower extremity strength & - & 5 & 5 & 5 & 4 & 4 & 5 - to 5 \\
\hline Reflexes & $2+$ & Trace & $2+$ & $1+$ to $2+$ & $1+$ to $2+$ & $2+$ & $2+$ \\
\hline FVC (\% predicted) & - & - & - & - & $2.72 \mathrm{~L}(83 \%)$ & $2.87 \mathrm{~L}(75 \%)$ & $3.03 \mathrm{~L}(56 \%)$ \\
\hline Echocardiogram (ejection fraction) & Normal & - & Normal (55\%) & Angiogram normal & Normal $(>55 \%)$ & $\sim 45 \%$ & $(>55 \%)$ \\
\hline Creatine kinase $(\mathrm{U} / \mathrm{L})$ & 5,438 & $5,000+$ & 1,945 & 3-4 times normal & 1,136 & 5,031 & 6,560 to 10,642 \\
\hline Dystrophin duplication/deletion & None & - & None & None & - & - & - \\
\hline Age at biopsy & $3 \mathrm{I} / 2$ years & 17 years & 30 years & 51 years & 27 years & 25 years & - \\
\hline Muscle sampled & Left quadriceps & Left biceps & Deltoid & Left quadriceps & Biceps & Deltoid & - \\
\hline Dystrophin staining & Normal & Normal & Normal & Normal & Normal & Normal & - \\
\hline Merosin staining & Normal & - & - & - & - & Decreased & - \\
\hline Sarcoglycans $(\alpha, \beta, \gamma, \delta)$ & Normal & Normal & Normal & - & Normal & Normal & - \\
\hline$\beta$-dystroglycan & Normal & - & Normal & - & Normal & Normal & - \\
\hline Spectrin & - & Normal & Normal & - & Normal & Normal & - \\
\hline FKRP mutation & $\begin{array}{l}\text { c.826C>A, p.L2761 } \\
\text { (homozygous) }\end{array}$ & $\begin{array}{l}\text { c.826C>A, p.L2761 } \\
\text { (homozygous) }\end{array}$ & $\begin{array}{l}\text { c.826C>A, p.L2761 } \\
\text { (homozygous) }\end{array}$ & $\begin{array}{l}\text { c. } 826 C>A, p . L 2761 \\
\text { (homozygous) }\end{array}$ & $\begin{array}{l}\text { c.826C>A, p.L2761 } \\
\text { (homozygous) }\end{array}$ & $\begin{array}{l}\text { c. } 826 C>A, p . L 2761 \\
\text { (homozygous) }\end{array}$ & $\begin{array}{l}\text { del 1006-1174 (169 } \\
\text { basepair frameshift, } \\
\text { heterozygous), } \\
\text { c.328C>T, p.RI I0W } \\
\text { (heterozygous) }\end{array}$ \\
\hline
\end{tabular}


possibly rivaling LGMD2A (calpainopathy) in prevalence[10]. In particular, the homozygous c.826C>A, p.L276I mutation is the most common FKRP mutation in several series of Caucasian populations [8-10,12-15]. There is only one study to date that suggests otherwise, listing compound heterozygotes involving the c.826C>A mutation as being most abundant[11]. The homozygous form of the common mutation causes the milder phenotype of LGMD2I with onset in childhood or early adulthood and a slow progression. Ambulation appears to be preserved until at least middle age, suggesting that some affected individuals may not seek medical attention and may not be diagnosed due to the mild nature of their symptoms. The more severe phenotypes (severe LGMD2I, MDC1C, Walker-Warburg syndrome, and muscle-eyebrain disease) are generally caused by other mutations. There have been recent reports of patients with LGMD2I having previously been diagnosed incorrectly with a dystrophinopathy, thus it is important to confirm a molecular diagnosis for any of the muscular dystrophies[9].

A clinical comparison of the patients in our series to those in others is best made by focusing on the patients who have the common homozygous c.826C>A mutation[8$10,12,13]$. The clinical courses of these patients to date correlate well across the series, especially with regard to the preservation of ambulation in most individuals into middle adulthood. The age of onset in several of our patients is at the earlier end of the range observed previously. In our series, cardiac and pulmonary complications are present in a minority of patients, consistent with another series[15]. However, some of our subjects have not yet been screened for these conditions, and other series suggest a high prevalence of both complications $[16,17]$.

\section{Conclusion}

LGMD2I may be one of the more common forms of LGMD in some North American populations. The most common mutation generally cause a mild phenotype, but these patients have clearly elevated creatine kinase levels, making it easy to screen for this disorder in patients with mild gait difficulties. As further cohorts of LGMD patients are analyzed, the incidence of each subtype will become more clearly defined.

\section{List of abbreviations used}

FKRP, fukutin-related protein

LGMD, limb-girdle muscular dystrophy

MDC1C, congenital muscular dystrophy type 1C

\section{Competing interests}

The author(s) declare that they have no competing interests.

\section{Authors' contributions}

All authors have read and approved the final manuscript.

PBK helped select subjects to be studied, analyzed data, and drafted and edited the manuscript.

CAF performed PCR reactions, prepared sequencing reactions, analyzed data, and helped edit the manuscript.

EE managed patient databases, helped select subjects to be studied, and helped edit the manuscript.

MT managed patient databases, advised on technical issues, and helped analyze data.

AJW performed PCR reactions, prepared sequencing reactions, and analyzed data.

BTD contributed subject information and clinical background, and helped edit the manuscript.

AAA contributed subject information and clinical background, and helped edit the manuscript.

LMK supervised the project, providing advice and guidance on all aspects of the study, and helped edit the manuscript.

\section{Acknowledgements}

The authors thank Richard R. Bennett and Jillian K. LeBlanc for technical assistance. This project was funded by NINDS K08 NS048I80 (PBK), NIH P0I NS40828-0IAI (LMK), the Bernard and Alva B. Gimbel Foundation (LMK), and the Joshua Frase Foundation (LMK). LMK is an Investigator of the Howard Hughes Medical Institute.

\section{References}

I. Esapa CT, Benson MA, Schroder JE, Martin-Rendon E, Brockington M, Brown SC, Muntoni F, Kroger S, Blake DJ: Functional requirements for fukutin-related protein in the Golgi apparatus. Hum Mol Genet 2002, I I(26):33 I9-333I.

2. Matsumoto H, Noguchi S, Sugie K, Ogawa M, Murayama K, Hayashi YK, Nishino I: Subcellular localization of fukutin and fukutinrelated protein in muscle cells. J Biochem (Tokyo) 2004, |35(6):709-7|2.

3. Esapa CT, Mcllhinney RA, Blake DJ: Fukutin-related protein mutations that cause congenital muscular dystrophy result in ER-retention of the mutant protein in cultured cells. Hum Mol Genet 2005, I 4(2):295-305.

4. Torelli S, Brown SC, Brockington M, Dolatshad NF, Jimenez C, Skordis L, Feng LH, Merlini L, Jones DH, Romero N, Wewer U, Voit T, Sewry CA, Noguchi S, Nishino I, Muntoni F: Sub-cellular localisation of fukutin related protein in different cell lines and in the muscle of patients with MDCIC and LGMD2I. Neuromuscul Disord 2005, I 5( I 2):836-843.

5. Dolatshad NF, Brockington M, Torelli S, Skordis L, Wever U, Wells DJ, Muntoni F, Brown SC: Mutated fukutin-related protein (FKRP) localises as wild type in differentiated muscle cells. Exp Cell Res 2005, 309(2):370-378. 
6. Brockington M, Blake DJ, Prandini P, Brown SC, Torelli S, Benson MA, Ponting CP, Estournet B, Romero NB, Mercuri E, Voit T, Sewry CA, Guicheney $P$, Muntoni $F$ : Mutations in the fukutin-related protein gene (FKRP) cause a form of congenital muscular dystrophy with secondary laminin alpha2 deficiency and abnormal glycosylation of alpha-dystroglycan. Am J Hum Genet 200I, 69(6):। I 198-1209.

7. Beltran-Valero de Bernabe D, Voit T, Longman C, Steinbrecher A, Straub V, Yuva Y, Herrmann R, Sperner J, Korenke C, Diesen C Dobyns WB, Brunner HG, van Bokhoven H, Brockington M, Muntoni $\mathrm{F}$ : Mutations in the FKRP gene can cause muscle-eye-brain disease and Walker-Warburg syndrome. J Med Genet 2004, 4I(5):e6I.

8. Brockington $M$, Yuva $Y$, Prandini P, Brown SC, Torelli S, Benson MA, Herrmann R, Anderson LV, Bashir R, Burgunder JM, Fallet S, Romero N, Fardeau M, Straub V, Storey G, Pollitt C, Richard I, Sewry CA, Bushby K, Voit T, Blake DJ, Muntoni F: Mutations in the fukutinrelated protein gene (FKRP) identify limb girdle muscular dystrophy $2 \mathrm{I}$ as a milder allelic variant of congenital muscular dystrophy MDCIC. Hum Mol Genet 200I, I (25):285I-2859.

9. Schwartz M, Hertz JM, Sveen ML, Vissing J: LGMD2I presenting with a characteristic Duchenne or Becker muscular dystrophy phenotype. Neurology 2005, 64(9): I635-1637.

10. Sveen ML, Schwartz M, Vissing J: High prevalence and phenotype-genotype correlations of limb girdle muscular dystrophy type 21 in Denmark. Ann Neurol 2006, 59(5):808-8I5.

II. Mercuri E, Brockington M, Straub V, Quijano-Roy S, Yuva Y, Herrmann R, Brown SC, Torelli S, Dubowitz V, Blake DJ, Romero NB, Estournet B, Sewry CA, Guicheney P, Voit T, Muntoni F: Phenotypic spectrum associated with mutations in the fukutin-related protein gene. Ann Neurol 2003, 53(4):537-542.

12. Frosk P, Greenberg CR, Tennese AA, Lamont R, Nylen E, Hirst C, Frappier D, Roslin NM, Zaik M, Bushby K, Straub V, Zatz M, de Paula F, Morgan K, Fujiwara TM, Wrogemann K: The most common mutation in FKRP causing limb girdle muscular dystrophy type 2I (LGMD2I) may have occurred only once and is present in Hutterites and other populations. Hum Mutat 2005, 25(I):38-44

13. Poppe M, Cree L, Bourke J, Eagle M, Anderson LV, Birchall D, Brockington M, Buddles M, Busby M, Muntoni F, Wills A, Bushby K: The phenotype of limb-girdle muscular dystrophy type 21 . Neurology 2003, 60(8):|246-|25|.

14. Moore SA, Shilling C], Westra S, Wall C, Wicklund MP, Stolle C, Brown CA, Michele DE, Piccolo F, Winder TL, Stence A, Barresi R, King N, King W, Florence J, Campbell KP, Fenichel GM, Stedman HH, Kissel JT, Griggs RC, Pandya S, Mathews KD, Pestronk A, Serrano C, Darvish D, Mendell JR: Limb-girdle muscular dystrophy in the United States. J Neuropathol Exp Neurol 2006, 65( I 0):995-I003.

15. Walter MC, Petersen JA, Stucka R, Fischer D, Schroder R, Vorgerd $M$, Schroers A, Schreiber H, Hanemann CO, Knirsch U, Rosenbohm A, Huebner A, Barisic N, Horvath R, Komoly S, Reilich P, Muller-Felber W, Pongratz D, Muller JS, Auerswald EA, Lochmuller H: FKRP (826C $>$ A) frequently causes limb-girdle muscular dystrophy in German patients. J Med Genet 2004, 4 I (4):e50.

16. Poppe M, Bourke J, Eagle M, Frosk P, Wrogemann K, Greenberg C, Muntoni F, Voit T, Straub V, Hilton-Jones D, Shirodaria C, Bushby K: Cardiac and respiratory failure in limb-girdle muscular dystrophy 21. Ann Neurol 2004, 56(5):738-74I.

17. Gaul C, Deschauer M, Tempelmann C, Vielhaber S, Klein HU, Heinze HJ, Zierz S, Grothues F: Cardiac involvement in limb-girdle muscular dystrophy $2 I$ : conventional cardiac diagnostic and cardiovascular magnetic resonance. I Neurol 2006, 253(10): $1317-1322$.

\section{Pre-publication history}

The pre-publication history for this paper can be accessed here:

http://www.biomedcentral.com/1471-2474/8/115/pre $\underline{\mathrm{pub}}$

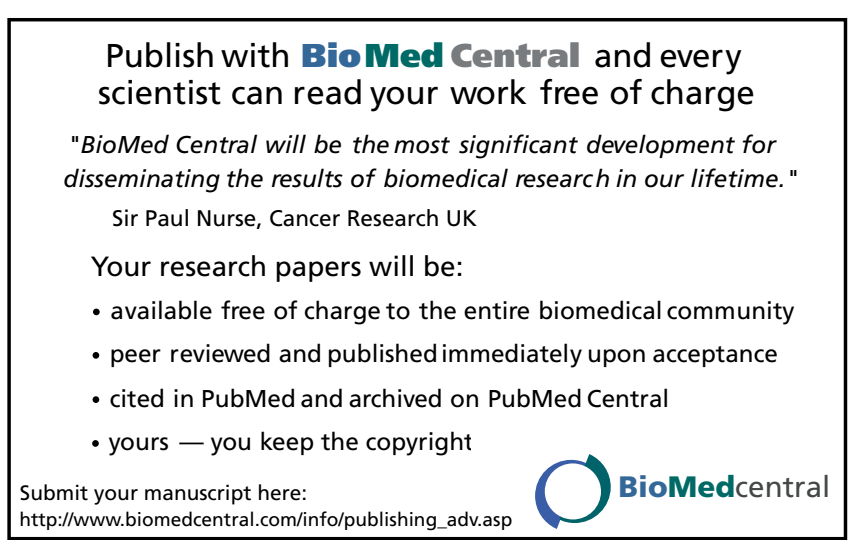

